\title{
The significance of the polycystic ovary
}

\author{
DAVID FerRIMAN \\ D.M., F.R.C.P. \\ Regional Endocrine Centre, North Middlesex Hospital, London, N.18
}

THE polycystic ovary is found in a variety of clinical situations and probably has a multiple aetiology. It is a physical sign rather than a disease entity.

Leaving aside the multiple luteinized cysts found in chlorionepithelioma and hydatidiform mole, the polycystic ovary is found with three main clinical presentations. One group of patients presents with oligomenorrhoea or amenorrhoea, anovulatory cycles and hirsuties. The second is similar but is not hirsute. The third presents often, but not invariably, around the menopause with menorrhagia and endometrial hyperplasia. This latter group has not received the attention which it deserves.

The rest of this paper will be confined essentially to the groups with oligomenorrhoea or amenorrhoea.

\section{Clinical picture}

Though patients classically present with secondary oligomenorrhoea or amenorrhoea, some have primary amenorrhoea and others present with bouts of menorrhagia. Infertility is common but not invariable, and tends to be relative rather than absolute. Hirsuties is common but by no means invariable. Some quantitative findings on the incidence of hirsuties in the polycystic ovary syndrome are of interest.

A semi-quantitative method for scoring the degree of body hair growth has been described (Ferriman \& Gallwey, 1961). Figure 1 shows the percentage incidence of the various scores obtained in a control series of 161 women between the ages of 18-38. Most clinicians would probably recognize hair scores 0-3 as corresponding to the concept of a normal non-hirsute female distribution, and figures of 10 and upwards as hirsutism. There is however a very interesting borderline group with scores between 4 and 9 which would be difficult to classify on a simple hirsute/non-hirsute basis.

Table 1 contrasts the percentage incidence of hair scores $0-4,5-9$ and 10 or above in the control series, with the incidence in 100 patients with infertility associated with oligomenorrhoea or amenorrhoea. There is a clear connection between hair score and infertility, and this connection is clearly visible. If hair scores 0-4 are contrasted with

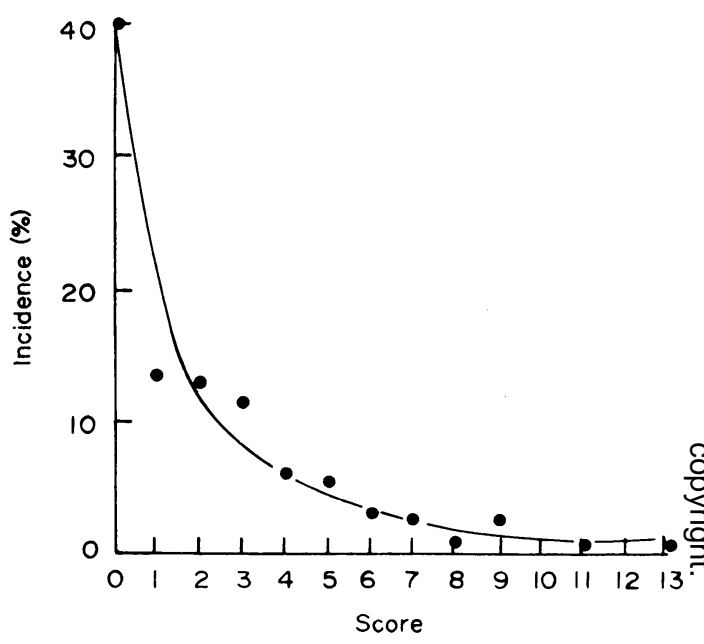

FIG. 1

TABLE 1. Incidence of hair scores 0-4, 5-9 and 10 upwards in a control series of 161 women, and in 100 from the writer's series of patients with anovulatory infertility

\begin{tabular}{lrrc}
\hline & $0-4$ & $5-9$ & $>10$ \\
\hline Controls & 90 & 9 & 1 \\
$\begin{array}{l}\text { Anovulatory } \\
\text { infertility }\end{array}$ & 33 & 32 & 35 \\
\hline
\end{tabular}

5 and upwards, the ratio which is $10: 1$ in the control series becomes $1: 2$ in the patients with $\frac{D}{O}$ anovulatory infertility. The aetiology of anovulatory infertility in two-thirds of the writer's series appears $N$ to be associated in some way or other with hirsutism.

Ovaries from 100 anovulatory patients in the writer's series have been classified as either large and presumably polycystic or normal (Ferriman \& Purdie, 1965). Table 2 contrasts the numbers of 0 large and normal sized ovaries in the three hair-score groups $0-3,4-9$ and 10 or above. The two groups contrast strongly, numbers in the hair-score groups rising steadily in the large ovary group, dropping in the normal group; the difference begins to appear 
TABLE 2. Incidence of hair scores 0-3, 4-9 and 10 upwards in fifty-four patients with large presumed polycystic ovaries, and forty-six with normal sized ovaries

\begin{tabular}{lrcc}
\hline & $0-3$ & $4-9$ & $>10$ \\
\hline Large & 9 & 20 & 25 \\
Normal & 23 & 15 & 8 \\
\hline
\end{tabular}

in the 4-9 group. Classifying hair-score groups 4 upwards as hirsute, and the rest as non-hirsute, it appears that five out of six patients with polycystic ovaries were hirsute and that hirsute patients were twice as likely to have large as opposed to normal sized ovaries. This suggests a strong connection between hirsuties and polycystic ovaries.

\section{Pathology}

Polycystic ovaries are usually larger than normal, but a proportion are normal in size. They are usually bilaterally enlarged, but are occasionally enlarged on one side only. The ovarian capsule is thickened, which may have an important bearing on response to treatment. The ovary contains multiple small follicular cysts. The theca interna is classically hyperplastic, but may occasionally be luteinized. Corpora lutea are sometimes present. The stroma is usually normal but occasionally may be hyperplastic.

\section{Laboratory findings.}

Oestrogen excretion is within normal limits. $\mathrm{C}_{19}$ steroid production is moderately increased. Cyst fluid contains an excess of $\mathrm{C}_{19}$ steroids, and a deficit of oestrogen. LH levels may be slightly elevated but the most striking feature is an absence of ovulatory surges in gonadotrophin production.

\section{Diagnosis}

Only $50 \%$ of polycystic ovaries can be detected by vaginal examination and recourse must be had to other methods. Gynaecographic demonstration of bilaterally enlarged ovaries is strongly suggestive of polycystic change but is not conclusive. Laparoscopy (or culdoscopy) is better in that it permits determination of the nature of the ovarian change by inspection and biopsy; it is particularly useful with unilateral enlargement or when the ovaries are of normal size.

\section{Aetiology}

The unusual $\mathrm{C}_{19}$ steroid/oestrogen findings in cyst fluid originally suggested a biosynthetic enzyme deficiency analogous to that in congenital adrenal hyperplasia. The demonstration that these cyst fluid findings reverted to normal on exhibition of human follicle-stimulating hormone (HFSH) and chorionic gonadotrophin (CG) by Crooke et al. (1963), and the more recent demonstration of restoration of ovulation and relief of infertility following clomiphene or HFSH-CG therapy forced an abandonment of this hypothesis. The ovaries themselves appear potentially normal and an explanation must be sought elsewhere.

The menstrual cycle is controlled from two centres in the hypothalamus. One, located in the median eminence is responsible for a steady basal production of gonadotrophins. The other, in the pre-optic area, in the female causes surges of gonadotrophin secretion responsible for ovulation. In the male these surges of activity do not occur due it is believed to a foetal masculinization of the pre-optic centre by the higher levels of testosterone production in the male. FSH leads to maturation of the follicle and the surge of LH production to ovulation, luteinization and eventual atresia of the follicles. Oestrogen produced under gonadotrophin stimulation leads not only (with progesterone) to endometrial maturation, but also to inhibition of hypothalamic activity.

Examination of some of the experimental situations in which polycystic ovaries are produced suggests aetiological possibilities for their clinical occurrence. These experimental situations are as follows:

(1) Injections of FSH.

(2) Parabiont experiments.

(3) Transplantation of ovaries into the spleen.

(4) Experimental lesions in the pre-optic area.

(5) Transplantation of ovaries into adult male rats.

(6) Injection of testosterone into newborn female rats.

The loss of oestrogen feed-back in situations 2 and 3 leads to a continuous overproduction of FSH. Situations 4, 5 and 6 are all thought to be due to elimination of ovulatory surges of gonadotrophin production, with the result that a continuous basal production of gonadotrophins results in follicular development without subsequent ovulation, corpus luteum formation and eventual atresia. That the pre-optic area has been altered by testosterone injection in situation 6 can be demonstrated by stimulation of the pre-optic area which has no effect, and of the median nuclei which leads to ovulation (Barraclough, 1961).

It would appear then that various influences acting on the hypothalamus can result in the formation of polycystic ovaries. It is suggested that this is the situation in the polycystic ovary syndrome. It is necessary to determine the nature of the operative causes.

The connection between hirsutism and polycystic ovaries can now be re-examined. On the original hypothesis the prime disturbance was thought to be ovarian, masculinizing $\mathrm{C}_{19}$ steroids were thought to 
originate from the ovary and hirsutism was secondary to this. Recent work (Baird, unpublished; Bardin, Hembree \& Lipsett, 1968; Jeffcoate et al., 1968) based on 'marker' steroids - cortisol for the adrenal cortex, oestrogens for the ovary-has suggested that the major source of testosterone in primary hirsuties with as well as without polycystic ovaries comes from the adrenal cortex. It is suggested that the prime fault, probably constitutional in nature, lies in the adrenal cortex and that the excess testosterone production has an effect on the pre-optic area similar to that in newborn female rats. Polycystic ovaries in this group of patients are secondary to the hypothalamic disturbance.

It remains to account for polycystic ovary formation in the smaller group of non-hirsute patients. Psychological disturbances acting on the hypothalamus are a possibility, though the writer knows of no evidence on this matter. If this explanation fails to hold water it must be admitted that the precise aetiology is unknown.

\section{Treatment}

The treatment of anovulatory infertility receives detailed attention in later papers. However, the treatment of patients with polycystic ovaries presents special points of interest.

Clomiphene or HFSH-CG has largely displaced other forms of treatment. Clomiphene is cheaper and easier to use but in unselected series is less effective leading to relief of infertility in only $25 \%$ of patients. HFSH-CG therapy is very expensive in both material and manpower, but is more effective leading to relief of infertility in $50 \%$ of unselected series of patients. However, patients with polycystic ovaries are a selected group and their response to clomiphene is considerably more favourable.

There is general agreement that patients may be classified into 'high' and 'low' oestrogen groups, the former responding to clomiphene much more favourably than the latter. In fact the relief of infertility in the high oestrogen group is no better with HFSH-CG than with clomiphene (Rabau, 1967). The characteristics of these two groups are shown in Table 3.

Tables 4 and 5 shows the duration of the menstrual cycle correlated with large and small ovaries,

TABLE 3. Characteristics of 'high' and 'low' oestrogen group

\begin{tabular}{|c|c|c|}
\hline $\begin{array}{l}\text { Oestrogen } \\
\text { group }\end{array}$ & 'High' & 'Low' \\
\hline $\begin{array}{l}\text { Oestrogen excretion } \\
(24 \mathrm{hr}) \\
\text { Duration of }\end{array}$ & $>10 \mu \mathrm{g}$ & $<10 \mu_{\mathrm{g}}$ \\
\hline $\begin{array}{l}\text { menstrual cycle } \\
\text { Endometrium }\end{array}$ & $\begin{array}{c}<6 / 12 \\
\text { Proliferative }\end{array}$ & $\begin{array}{r}>6 / 12 \\
\text { Atrophic }\end{array}$ \\
\hline
\end{tabular}

TABLE 4. Correlation between duration of menstrual cycle and size of ovaries

\begin{tabular}{ccc}
\hline & \multicolumn{2}{c}{ Ovarian size } \\
\cline { 2 - 3 } $\begin{array}{c}\text { Duration } \\
\text { of cycle }\end{array}$ & Large & Small \\
\hline$<6 / 12$ & 33 & 20 \\
$>6 / 12$ & 15 & 38 \\
\hline
\end{tabular}

TABLE 5. Correlation between duration of menstrual cycle and hair score

\begin{tabular}{lrrr}
\hline & \multicolumn{3}{c}{ Hair score } \\
\cline { 2 - 4 } $\begin{array}{c}\text { Duration } \\
\text { of cycle }\end{array}$ & $0-3$ & $4-9$ & $>10$ \\
\hline$<6 / 12$ & 14 & 24 & 27 \\
$>6 / 12$ & 17 & 10 & 7 \\
\hline
\end{tabular}

and with hair scores $0-3,4-9$ and 10 or above. These suggest that patients with polycystic ovaries or a tendency to hirsuties belong to the favourable 'high' oestrogen group. This is borne out by the response to treatment with clomiphene. Table 6 shows the correlation between an ovulatory response to clomiphene and the duration of the menstrual cycle, the size of the ovaries and the degree of hain growth. The figures are remarkably similar for at three parameters, suggesting that patients with moderate oligomenorrhoea, polycystic ovaries and hirsuties may constitute a disease entity. Table 7 shows the correlations between the relief of infertility and the same three parameters. Again a similar pattern emerges.

TABLE 6. Correlation between ovulatory behaviour following clomiphene and various parameters

\begin{tabular}{ccc}
\hline & Ovulatory & Anovulatory \\
\hline$<6 / 12$ & 22 & 2 \\
$>6 / 12$ & 11 & 17 \\
Ovarian size & 21 & 2 \\
Large & 11 & 18 \\
Normal & & 7 \\
Hair score & 27 & 12 \\
$>4$ & 6 & \\
$0-3$ & & \\
\hline
\end{tabular}

TABLE 7. Correlation between occurrence of pregnancy following clomiphene and various parameters

\begin{tabular}{lrc} 
& Pregnancy & No pregnancy \\
\hline Duration of menstrual cycle & & \\
$<6 / 12$ & 18 & 14 \\
$>6 / 12$ & 4 & 21 \\
Ovarian size & & \\
$\quad$ Large & 14 & 12 \\
$\quad$ Normal & 6 & 16 \\
Hair score & & \\
$>4$ & 18 & 14 \\
$0-3$ & 4 & 13 \\
\hline
\end{tabular}


It is tempting to suggest that 'high' oestrogen patients with normal basal levels of oestrogen are associated with disturbances of the pre-optic area alone leaving basal production of gonadotrophins unaffected. This would fit in well with the concept of an androgenization of the pre-optic area by an excessive adrenocortical secretion of $\mathrm{C}_{19}$ steroids. More serious involvement of median nuclei leading to impaired production of gonadotrophins would correlate better with low oestrogen levels and an atrophic endometrium.

It will be noted that while the percentage of patients with polycystic ovaries ovulating in response to clomiphene is high-in the order of $90 \%$ - only some $50 \%$ obtain relief of infertility. The explanation is obscure. Steptoe (personal communication) has observed anomalies of ovulation in such patients, apparently related to thickening of the ovarian capsule. The development of these capsules has probably taken place over a number of years, and possibly treatment with clomiphene must be persisted with longer than is usually practised to secure regression of these changes.

The writer now treats single girls with polycystic ovaries routinely by clomiphene in the hope that the capsular changes will have disappeared by the time that marriage and a desire for children have arrived.
Gynaecography has been repeated after 1-2 years of treatment in three patients and the ovaries have decreased considerably in size though they are still not within the normal range.

\section{References}

Bardin, C.W., Hembree, W.C. \& Lipsett, M.B. (1968) Suppression of testosterone and androstenedione production rates with dexamethasone in women idiopathic hirsutism and polycystic ovaries. Journal of Clinical Endocrinology, 28, 1300.

Barraclough, C.A. (1961) Production of anovulatory sterile rats by injection of testosterone proprionate. Endocrinology, 68, 62.

Crooke, A.C., Butt, W.R., Palmer, R., Morris, R., Edwards, R.L., TAYlor, C.W. \& ShORT, R.V. (1963) Effect of human pituitary follicle-stimulating hormone and chorionic gonadotrophin in Stein-Leventhal syndrome. British Medical Journal, 1, 1119.

Ferriman, D. \& Gallwey, J.D. (1961) Clinical assessment of body hair growth in women. Journal of Clinical Endocrinology, 21, 1440.

Ferriman, D. \& Purdie, A.W. (1965) Association of oligomenorrhoea, hirsuties and infertility. British Medical Journal, $2,69$.

JefFcoate, S.L., Brooks, R.V., London, D.R., Prunty, F.T.G. \& RHODES, P. (1968) Secretion of $\mathrm{C}_{19}$-steroids and oestrogens in the polycystic ovary syndrome. Endocrinology, 42, 229.

Rabau, E., Serr, D.M., Mashiach, S., Insler, V., Salomy, M. \& Lunenfeld, B. (1967) Current concepts in the treatment of anovulation. British Medical Journal, 4, 446. 